Journal of Engineering and Applied Sciences 15 (1): 291-298, 2020

ISSN: 1816-949X

(C) Medwell Journals, 2020

\title{
Managing Local Community Participation to Foster Sustainable Tourism Development, the Case of Bali Destination, Indonesia
}

\author{
I. Gede Sujana Budhiasa and I. Gede Riana \\ Faculty of Economics and Business, University of Udayana, Bali, Indonesia
}

\begin{abstract}
Local residents' participation can take part as strategic key for the quality of tourism destination toward sustainable tourism development. By involving the local communities participation and supporting the quality of tourism destination that is believed enhancing the communities' well-being through increasing people income and job creation. The recidents' participation in tourism can be jointly togetherness with local government in accelerating the quality tourism destination. This study is maka an effort to find the effect of government policies and local residents' involvement to create sustainable tourism development in selected tourism destination area in northern Bali Region. A structural equation model was built and data were collected from tourism destination location selected. Total of 241 respondent were selected from local resident using self-administered questionnaire. The study revealed the local participation is significantly influenced by the government policy and can be concluded that clocal community participation jointly with government policy successful support and positively contributed the quality of tourism destination toward sustainable tourism development.
\end{abstract}

Key words: Bali, local residents' perceptions toward community participation, quality of destination, sustainable tourism development, government policy, strategic key

\section{INTRODUCTION}

Tourism has become one of the activity sectors that have generated the most value added. Moreover, it is the principal economic source in many areas in the world. Tourism destination and competition hase been the strategic issues as instrument to generate people income and job creation.

Brida et al. (2010) note that local residents are the most important participant who are critically influenced of positive as well negative impacts of tourism development in their yard. Residents' perceptions towards tourism are so crucial as they are directly impacted by development (Easterling, 2005) and tourism development supported by stakeholder become more sustainable (Byrd, 2007).

Most of all, implementation of sustainable development policy globally proves the necessity to consider the regional level as the key in terms of developing and implementing modern models of sustainable development (Mishenin et al., 2018). Viewed from economic perspective, tourism has been proven give benefits for the local community through increasing their income, providing new job opprtunity as well creating new business for the local.

In addition, Croes (2014) argued that tourism is considered as the tools of reducing poverty in some traditional communities with more tourists coming to buy local products (Lee, 2013). However, rural community and culture could be considered as the basic requirement for the participatory management of destination sustainability (Clausen and Gyimothy, 2016) as well as opportunities to increase employment and generating local people income (Lee, 2013).

In Indonesia, inspite of the isues of sustainability have moved into political agenda, the progress remains slow (Rajiani and Kot, 2018) so it is sensible that is although a lot of efforts and progress has been done by the central and local authorities of Bali Province to promote Sustainable Tourism Development (STD), the outcomes were still questionable. Refer to Mowforth and Munt (2015), the understanding of their social structure is an important factor to warrant the successfulness of STD.

Based on this premise, that the local government of Bali is assumed has an essential position to guide the local people in increasing the quality of tourists' destination. This study is directed to elaborate the roles of local govenment in Bali in promoting sustainable tourism development. Spesifically, this work studied the effect of the roles toward local participation, the local perception about tourism and its impacts on the daily life. Tourism provides direct and indirect economic benefits to destinations through visitor spending and business investments for encouraging people income and employment. But there is a little attention of many governments and others to understand that residents' perceptions of tourism have significant impacts on tourism destination competition. Brida et al. (2010) states that residents' perceptions have significant role to the tourism developmnet.

Corresponding Author: I. Gede Sujana Budhiasa, Faculty of Economics and Business, University of Udayana, Bali, Indonesia 
Residents' perceptions towards tourism are so crucial as they are directly impacted by development (Easterling, 2005) and tourism development supported by stakeholder become more sustainable (Byrd, 2007). Most of all, implementation of sustainable development policy globally proves the necessity to consider the regional level as the key in terms of developing and implementing modern models of sustainable development (Mishenin et al., 2018). Some researches have found that tourism contributes people income and employment. On the other hands, Croes (2014) argued that tourism is considered as the tools of reducing poverty in some traditional communities with more tourists coming to buy local products (Lee, 2013). However, rural community and culture could be considered as the basic requirement for the participatory management of destination sustainability (Clausen and Gyimothy, 2016), as well as opportunities to increase employment and generating local people income (Lee, 2013). However, local resident participation mostly the key for encouraging the successfulness of quality of destination support (Mowforth and Munt, 2015).

This continuing research focus on the same location at the North Bali Regions, Indonesia still believes that local government of Bali still have strategic key in supporting local community forces to maintain tourism destination to be more competitiveness in the future. This research has been continued focusing the role of resident's participation as the key variable in supporting and maintaining the quality of destination at North Bali Region in Indonesia.

Literature review: The assessment of tourism development focused on resident has been widely identified supporting residents and improved access to tourism industry (Lee, 2013; Wang et al., 2016). On the other hands, one important variable such as Individuals' perceptions could be the key for destination's personality in supporting destination quality process (Murphy et al., 2007).

Destination personality has therefore gained significant attention from tourism scholars. Chi et al. (2018) is reported on their intensive studies at Sardinia Italy have examines the role of involvement on destination personality formation process have found that the destination personality dimensions have strong influence on destination satisfaction and self-congruity. The destination satisfaction was also found to positively influence to construct positively the destination loyalty.

Resident's perception and local community can impact positively or negatively to the natural and local culture of society and could be connected to the society group identity of local resident (Kim et al., 2012).

The tourism destination support by government policy and residents' perception and community participation can be believe as instruments for creating local people income and employment creation. As a matter of facts, the studies of well-being tourism actually focused on connection with community, restaurant, local people service and some others form of tourism service (Pesonen and Komppula, 2010). Some empirical studies indicated local people well being as the direct impact or indirectly impact of well-being tourism destination's attractiveness. Community as part of destination service process and attractiveness successfully create local people well-being (Cracolici and Nijkamp, 2009).

Reitsamer et al. (2016) study focused on attractions, activities, entertainment and local community involvement in Austrian tourism destinations have found that tourists' well-being has a positive significant effects to local people, positive impact also captured on their intention to return, therefore, contributed positive word of mouth form the destination process and activity.

The more trending study of sustainable tourism in recent year indicated because of positively impact of tourism destination in supporting local people income (Law et al., 2016).

Mendieta-Penalver et al. (2018) argue that tourism destination competitiveness can be integrated approach with international hotel network to encourage tourist destination quality. Mendieta-Penalver et al. (2018) have empirically support of a positive relationship between destination competitiveness and firm competitiveness.

Reitsamer et al. (2016) reported the study impact of place perception on tourist well-being to understand how destination attributes influence tourists' response attitudes, summarizes that attractions and activities and service entertainment of local community. However, Reitsamer et al. (2016) have found that tourists' well-being has a significant impact to local people income and also have positively effect of their intention to return, so that, become more attractive effect on the desire to settle a positive word of mouth of the destination.

Lo et al. (2019) has reported on research study of community support as an integral part of tourism product in supporting tourism destination quality, especially in rural sector .

Lo et al. (2019) has found that sustainable development of rural tourism destination play an important role for developing rural tourism together with community participation. Compared with other research, Lo et al. (2019) significantly found that the competitiveness of rural tourism destination's development is depend on community support act as a moderator. It is mean that the quality of accommodation and some other related components. Such as infrastructure, attraction and special events empirically support positively for the development of tourism destination competitiveness in rural tourism destination at Serawak, Malaysia. 
Lee and Jan (2019) reported the community based study addressing by examining residents' perceptions of the sustainability of community-based tourism. Lee and Jan (2019) study about the residents' perceptions of economic impact, socio-cultural and environmental in Taiwan. This research have found that economic, cultural and environmental sustainability have strongly significant to the tourism destination quality.

Another studies have been conducted to investigate how residents perceive the impacts of tourism development at various tourism destinations (Kim et al., 2012), however, community participation can encourage local people income and employment opportunities (Nunkoo and Ramkissoon, 2011) and significantly contribute to positively of the traditional arts and crafts and culture (Jaafar et al., 2019).

The study concludes that the residents' perceptions differed across the developmental stages, thus, managers should consider the development opportunities and adopt appropriate strategies across different development stages. The quality of tourism destination that supporting by residents perception and its participation to be effective and cleaner tourism as in the island of Bali (Law et al., 2016). Some studies on sustainable development tourism have more focused on local residents' perception of community-based and pro-poor tourism or on the discussion of positive and negative impacts of tourism on economic development (Pulido-Fernandez et al., 2015) as well as on income redistribution among group and region (Alam and Paramati, 2016; Incera and Fernandez, 2015) and poverty reduction (Blake et al., 2003). However, developing countries have not yet managed to fully exploit their tourism potential (Sanches-Pereira et al., 2017).

\section{MATERIALS AND METHODS}

An initial sample of 241 respondent were selected and obtained from Lovina Beach Singaraja City, Northern of Bali. To examine the latent structure of reisdents' perception and community research model, SEM PLS was used in the present study. The goal of SEM PLS is to identify the underlying relationships between latent variables (Hair et al. 2010).

While CFA is primarily an exploratory technique used and CFA plays a confirmatory role enabling control over the specification of indicators for each latent dimension. The CFA also allows testing goodness of fit for the proposed extracted factor solution and is therefore, particularly useful in the validation of scales for the measurement of specific constructs and would be more better construct percistly (Jarvis et al, 2003). This research is located at Lovina Beach tourism destination, North Bali Region, Indonesia.
In this study, Lovina Beach of North Bali Indonesia is chosen as the research sites due to the destination choice of tourist popularity for tourists' visit over the past decade at Northern Bali Region. However, this study employs proportional random sampling techniques, that the probability of being chosen as participants (Walliman, 2011; Howell, 2013). This study used primary data and collected by questionnaires were distributed to the selected respondents at lovina beach destination, North Bali, Indonesia.

Respondents were asked to respond to each statement by using a five-point Likert scale (ranging from 1 strongly disagree to 5 with strongly agree) for each statement. To assess the model developed as shown in Fig. 1, SmartPLS 3.0 was applied based on path modeling and followed by bootstrapping model (Wetzels et al., 2009). As recommended by Hair et al. (2010), five hundred resamples were used to generate the standard error of the estimate and t-values. Population data were, however, the information sources that come from primary data collection known as construct must be examine and that construct is reliable if there is that the Cronbach's alpha value is at least 0.70 (Hair et al., 2010).

The SEM PLS was conducted on data set to support the theoretical verification of our constructs (Tenenhaus et al., 2005). The hypotheses were tested through structural equation modelling using SmartPls 3.0 The research model and hypotheses is shown at Fig. 1, that captured the relationship between constructs. This study is formulated four hypotheses that as follows:

Z1: Residents' perceived participation has positively affects to the quality of the tourism destination

Z2: Government policies positively affect tresidents' perceived participation

Z3: Government policies positively affect the quality of tourism destination

Z4: Quality tourism destination positively affects sustainable tourism development (Table 1)

On the average, ages of respondents are 43.8 years old. Most of the respondents had been completed their junior high school (65\%) and 18\% hold the diploma or undergraduate degree. Item validity and construct reliability for a latent variable with reflective indicators can be assessed by observing item correlation and Cronbach's alpha coefficient. We have first evaluate of second order construct of residents' participation that directly reflected by cultural impact, social impact and economic impact indicated distributed well by cronbach Alpha, that are greater than 0.70, however that can be conclude all of dimensional constructs are reliable. 


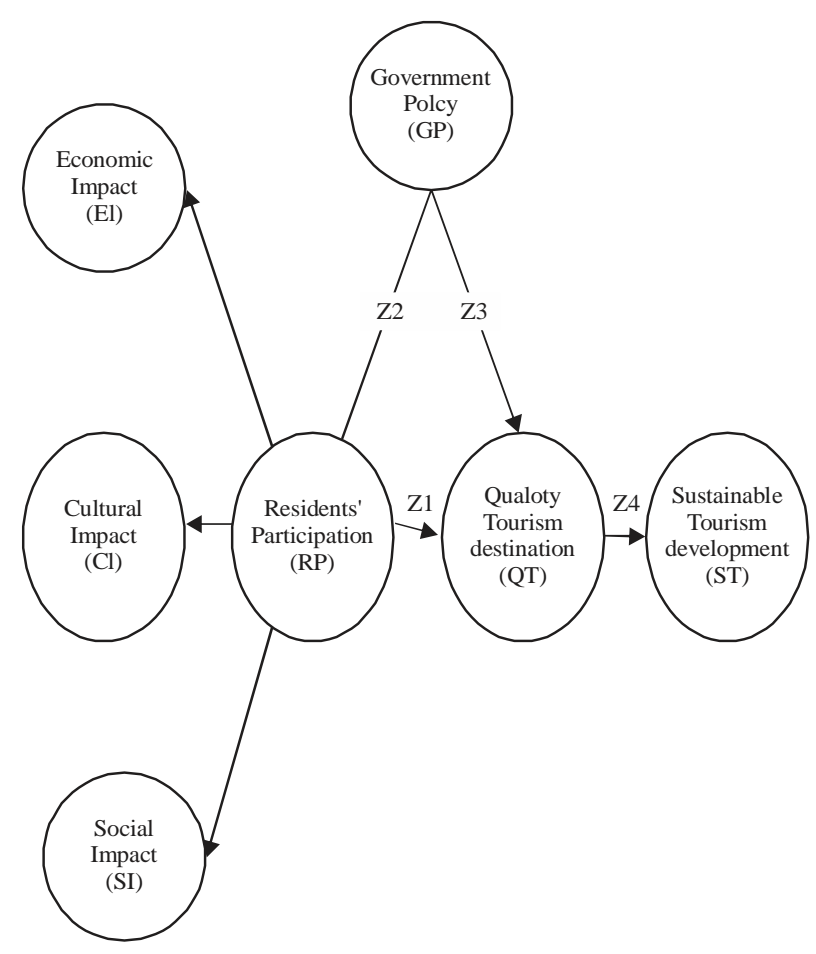

Fig. 1: Research model

\begin{tabular}{lccc}
\multicolumn{4}{l}{ Table 1: Destination area and sample distribution } \\
\hline Name of destination & Number of respondents & Percentage & Samples \\
\hline Banyuasri village & 87 & 14.40 & 35 \\
Anturan village & 70 & 11.59 & 28 \\
Baktiseraga village & 53 & 8.77 & 21 \\
Panji Anom village & 84 & 13.91 & 34 \\
Teluk Buluh village & 75 & 12.42 & 30 \\
Kayu Melaka village & 61 & 10.10 & 24 \\
Temukus village & 59 & 9.77 & 24 \\
Labuhan Haji village & 62 & 10.26 & 25 \\
Dencarik village & 53 & 8.77 & 21 \\
Total & 604 & 100.00 & 241 \\
\hline
\end{tabular}

We devided SEM PLS analysis into two approached model. Firstly, is outer model that contain construct procedure evaluation with its indicators. Secondly, is inner model approaches that contain bootstrapping procedure as the tools for statistical methods to solve the direct effect statistical testing procedure and the indirect effect statistical testing procedure.

Based on SEM PLS Model, construct can be developed in reflective or formative constructs. For reflective outer model, the statististical evaluation tesnting procedure based on the internal consistency approached that focusing on Composite Reliability (CA) testing procedure, the cronbch Alpha individual test and the testing of Average Variance Extracted (AVE) as evaluation of the convergence validity of one construct and furthermore, based on AVE value can be developed as the key value to compare with cross-correlation of all the constructs to find the Fornell-Larscker discriminant validfity.

Based on Table 2, we can conclude that all of the constructs have distributed value of Cronbach alpha are greater than 0.70 , so that, all contructs confirm sufficient reliability (Hair et al., 2010). Referring to Hair et al. (2016), the construct has an internal consistency if the $\mathrm{CR}$ is greater than 0.70 . The important measurement of one construct can be used AVE value that must be higher than 0.50 (Hair et al., 2016; Peng and Lai, 2012) that should be catagorized as convergence validity.

The continuing process of measurenment analysis can avoiding statstical error type and construct is to be convergent validity have more guarantee to get more satisfied data information. As recommendation note by Hair et al. (2010), the outer loading must be higher than 0.70 and significant (Peng and Lai, 2012). Based on Table 2, The AVE, CR and outer-loading and finally with $\mathrm{p}<5 \%$ would be satisfied internal consistency and supporting of discriminant validity issues.

As notes by Jarvis et al. (2003), research model must be consider the concept development of reflective and formative constructs. As presented in Table 2, all the construcs are summarized as reflective constructs and have been using reliability testing procedure by Cronbach alpha and others but as we can seen at Table 3, the formative construct of Government policy should be evaluate and examine using VIF collinearity testing procedure (Jarvis et al., 2003). Based on Table 3, we can seen that Government policy is formative construct, so 
J. Eng. Applied Sci., 15 (1): 291-298, 2020

Table 2: Reflective measurement model analysis result

\begin{tabular}{|c|c|c|c|c|c|}
\hline Construct & Average & CR & Item code & Outer loading & p-value \\
\hline \multirow[t]{4}{*}{ Cultural Impacts (CI 1.1) } & 0.81 & 0.85 & CI 1.11 & 0.812 & 0.000 \\
\hline & & & CI 1.12 & 0.829 & 0.000 \\
\hline & & & CI 1.13 & 0.877 & 0.000 \\
\hline & & & CI 1.14 & 0.944 & 0.000 \\
\hline \multirow[t]{4}{*}{ Social Impacts (SI 1.2) } & 0.76 & 0.79 & SI 1.21 & 0.815 & 0.000 \\
\hline & & & SI 1.22 & 0.833 & 0.000 \\
\hline & & & SI 1.23 & 0.912 & 0.000 \\
\hline & & & SI 1.24 & 0.848 & 0.000 \\
\hline \multirow[t]{4}{*}{ Economic Impacts (EI 1.3) } & 0.79 & 0.81 & EI 1.31 & 0.917 & 0.000 \\
\hline & & & EI 1.32 & 0.855 & 0.000 \\
\hline & & & EI 1.33 & 0.837 & 0.000 \\
\hline & & & EI 1.34 & 0.912 & 0.000 \\
\hline \multirow{3}{*}{ Quality of destination (QT 2) } & 0.72 & 0.78 & QT 2.1 & 0.899 & 0.000 \\
\hline & & & QT 2.2 & 0.847 & 0.000 \\
\hline & & & QT 2.3 & 0.911 & 0.000 \\
\hline \multirow{4}{*}{ Sustainable Tourism development (ST 3) } & 0.77 & 0.88 & ST 3.1 & 0.921 & 0.000 \\
\hline & & & ST 3.2 & 0.842 & 0.000 \\
\hline & & & ST 3.3 & 0.879 & 0.000 \\
\hline & & & ST 3.4 & 0.899 & 0.000 \\
\hline
\end{tabular}

Table 3: Formative construct testing procedure

\begin{tabular}{llcl}
\hline Construct & Code/Item description & Outer weight & VIF \\
\hline Government policies & GP 1.1formulates legal compliance & $0.377^{\text {ns }}$ & 3.12 \\
& GP 1.2 establish tourism planning & $0.471^{*}$ & 2.45 \\
& GP 1.3 improves public safety & $0.321^{\text {ns }}$ & 3.66 \\
GP 1.4 improves public infrastructures & $0.081^{\text {ns }}$ & 2.94 \\
\hline
\end{tabular}

that will evaluate using collinearity VIF testing procedure to evaluate whether government policy construct is valid and can be continue to the next step of inner model analyisis.

The formative construct can be evaluate using collinearity VIF procedure. Table 3 presented outer weight and VIF value of each indicator. Since, all indicators have distributed the VIF value are $<5$, so that, the collinearity issues does not exist in the government policy construct (Hair et al., 2016).

Inner model analysis: Our model results concern with PLS-SEM structural models' validity with assessed through the strength of regression weights, t-values, $\mathrm{p}$-values for significance of t-statistics. The $\mathrm{R}^{2}$ can be used as the tools to measure of the model's predictive accuracy. It represents the amount of variance in the endogenous constructs explained by all of the exogenous constructs linked to it.

According to Chin (1998), that the value of $\mathrm{Q}^{2}$ is $<1$ indicates that the model has good predictive relevance. The calculation of $\mathrm{Q}^{2}$ predictive relevance shows the value of 0.81 means that $81 \%$ variable of sustainable tourism development can be explained by government policy, resident's perception and the quality of tourism destination. The next final statistical analysis is based on interdeendent relationship between constructs that captured in Fig. 2 and at detail explanation in Table 4. We have found that four relationship support of 5\% significant level.

\section{RESULTS AND DISCUSSION}

We used covariance-based SEM as the tools for predicting and bootstrapping technique applied to estimate research model's of parameters. Smart PLS 3 version is applied (Ringle et al., 2015). Our regression analisys as presented in Table 4 shows that all the hypotheses were supported by the data. Specifically, it indicates that PLS-SEM residents' perception have significantly positive effect on improving quality of tourism destination and toward sustainable tourism development.

Our model results concern with structural relationship based on research hypothesis. We agree with Croes (2014) especially on the contribution of services and reputation and we also confirm with the relationship between economic development and tourism destination competitiveness. Our statistical estimation also have the same direction to the conclusions of weather, culture, events, tourist assessment, leisure supply, tourist infrastructure and accessibility to tourism destination area are so important and strategic key attributes.

The next step is the result of the quality tourism destination competitiveness, that so, important because an increase in destination competitiveness could be directly improve the destination's prosperity. Crouch We can conclude that the quality of tourism destination is directly linked to socio-economic prosperity (Fig. 2). Dwyer and Kim (2004) conclude that destination competitiveness supporting sustainable people income. 


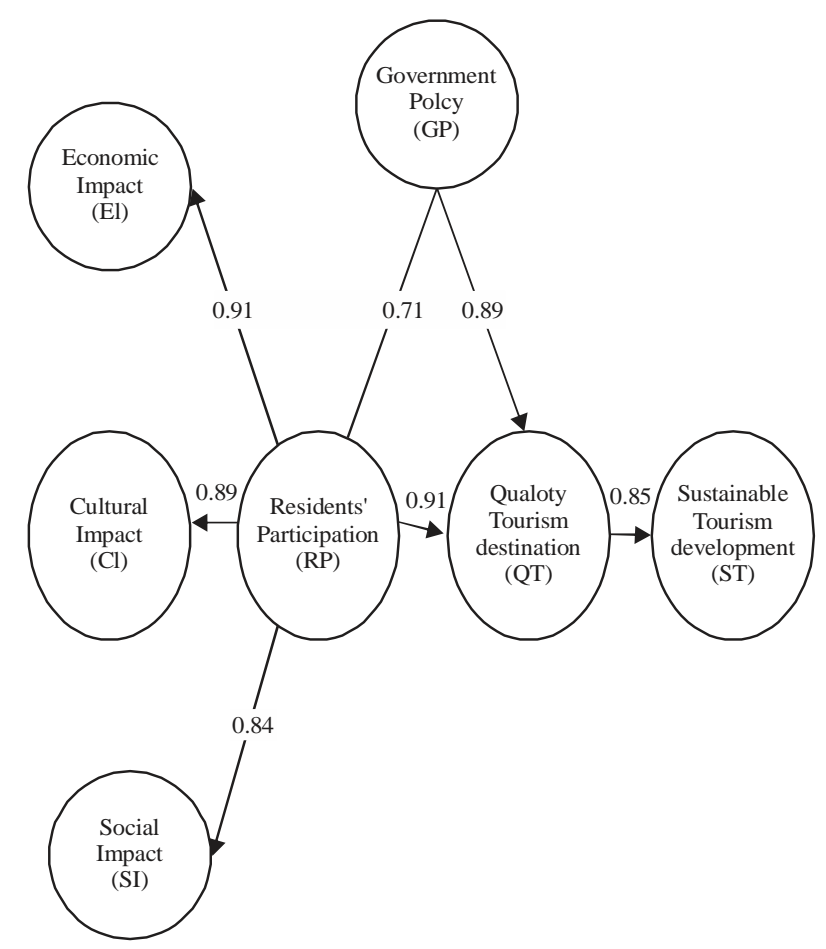

Fig. 2: Structural relationship model and Path values prediction

Table 4: Path coefficient and statistical test of direct effect

\begin{tabular}{lcccc}
\hline Description & Original sample (O) & SD & t-stats & p-values \\
\hline GP->RP & 0.71 & 0.310 & 2.290 & 0.022 \\
GP->QT & 0.89 & 0.410 & 2.171 & 0.030 \\
RP->QT & 0.91 & 0.330 & 2.758 & 0.006 \\
QT->ST & 0.85 & 0.240 & 3.542 & 0.000 \\
\hline
\end{tabular}

Hunt and Stronza (2014) state that destination tourism plan must be covered more resident managers to ensure that direct employment is provided to residents for carrying that tourism revenue distributed among the number of residents (Hunt and Stronza, 2014). The residents' perceptions were measured based on three dimensions such as economic impact, social impact and cultural impact. However, as recommended by Lee and Hsieh (2016), that the study of quality destination should be more covered with the role of stakeholder collaboration. This way, further research is necessary in understanding the main character and behavior of residents' perception and its significant impact to support the quality of tourism destination to be more sustainable tourism development.

\section{CONCLUSION}

The analysis that carried out in this research article has allowed us to observe the phenomenon of destination competitiveness especially in emerging market countries, such as Bali region, Indonesia. We have applied quantitative SEM PLS methods to measure residents' as part of community participation in supporting the competitiveness area of tourism destination.

This article more focused on research implications for fostering residents' perception toward participation for encouraging destination tourism service. However, our research analysis strongly indicates the opportunity of lccal resident and government policy stand for managing stakeholder to handle area of destinations that have the opportunity to increase tourism competitiveness by handling indicators such as economic impact, social impact and cuktural impact that would be taking the role as leveraging competitive advantages.

As we noted at the beginning discussion in this study, tourism is a the most important resource for Bali and other region in Indonesia, that mostly understanding the importance of tourism in the world economy and the value-added of increasing domestic product of one country.

\section{REFERENCES}

Alam, M.S. and S.R. Paramati, 2016. The impact of tourism on income inequality in developing economies: Does Kuznets curve hypothesis exist?. Ann. Tourism Res., 61: 111-126.

Blake, A., M.T. Sinclair and G. Sugiyarto, 2003. Quantifying the impact of foot and mouth disease on tourism and the UK economy. Tourism Econ., 9: 449-465. 
Brida, J.G., L. Osti and A. Barquet, 2010. Segmenting resident perceptions towards tourism-a cluster analysis with a multinomial logit model of a mountain community. Intl. J. Tourism Res., 12: 591-602.

Byrd, E.T., 2007. Stakeholders in sustainable tourism development and their roles: Applying stakeholder theory to sustainable tourism development. Tourism Rev., 62: 6-13.

Chi, C.G.Q., L. Pan and G. Del Chiappa, 2018. Examining destination personality: Its antecedents and outcomes. J. Destination Marketing Manage., 9: 149-159.

Chin, W.W., 1998. The partial least squares approach to structural equation modeling. Mod. Methods Bus. Res., 295: 295-336.

Clausen, H.B. and S. Gyimothy, 2016. Seizing community participation in sustainable development: Pueblos Magicos of Mexico. J. Cleaner Prod., 111: 318-326.

Cracolici, M.F. and P. Nijkamp, 2009. The attractiveness and competitiveness of tourist destinations: A study of Southern Italian regions. Tourism Manage., 30: 336-344.

Croes, R., 2014. The role of tourism in poverty reduction: An empirical assessment. Tourism Econ., 20: 207-226.

Dwyer, L. and S. Kemp, 2004. Closure of an ecolodge Poor strategic management?. J. Pacific Stud., 26: 51-75.

Easterling, D.S., 2005. The residents perspective in tourism research: A review and synthesis. J. Travel Tourism Marketing, 17: 45-62.

Hair Jr, J.F., G.T.M. Hult, C. Ringle and M. Sarstedt, 2016. A Primer on Partial Least Squares Structural Equation Modeling (PLS-SEM). Sage Publications, Thousand Oaks, California,.

Hair, J.F., W.C. Black, B.J. Babin and R.E. Anderson, 2010. Multivariate Data Analysis: A Global Perspective. 7th Edn., Pearson Education Inc., Upper Saddle River, NJ., USA., ISBN-13: 9780135153093, Pages: 800.

Howell, K.E., 2013. An Introduction to the Philosophy of Methodology. SAGE Publications, California, USA., ISBN:9781446290620, Pages: 248.

Hunt, C. and A. Stronza, 2014. Stage-based tourism models and resident attitudes towards tourism in an emerging destination in the developing world. J. Sustainable Tourism, 22: 279-298.

Incera, A.C. and M.F. Fernandez, 2015. Tourism and income distribution: Evidence from a developed regional economy. Tourism Manage., 48: 11-20.

Jaafar, M., S.M. Rasoolimanesh and S. Ismail, 2017. Perceived sociocultural impacts of tourism and community participation: A case study of Langkawi Island. Tourism Hospitality Res., 17: 123-134.
Jarvis, C.B., S.B. Mackenzie and P.M. Podsakoff, 2003. A critical review of construct indicators and measurement model misspecification in marketing and consumer research. J. Consumer Res., 30: 199-218.

Kim, J.H., J.B. Ritchie and B. McCormick, 2012. Development of a scale to measure memorable tourism experiences. J. Travel Res., 51: 12-25.

Law, A., T. de Lacy, G. Lipman and M. Jiang, 2016. Transitioning to a green economy: The case of tourism in Bali, Indonesia. J. Cleaner Prod., 111: 295-305.

Lee, T.H. and F.H. Jan, 2019. Can community-based tourism contribute to sustainable development? Evidence from resident's perceptions of the sustainability. Tourism Manage., 70: 368-380.

Lee, T.H. and H.P. Hsieh, 2016. Indicators of sustainable tourism: A case study from a Taiwan's wetland. Ecol. Indic., 67: 779-787.

Lee, T.H., 2013. Influence analysis of community resident support for sustainable tourism development. Tourism Manage., 34: 37-46.

Lo, M.C., C.H. Chin and F.Y. Law, 2019. Tourist's perspectives on hard and soft services toward rural tourism destination competitiveness: Community support as a moderator. Tourism Hospitality Res., 19: 139-157.

Mendieta-Penalver, L.F., J.F. Perles-Ribes, A.B. Ramon-Rodriguez and M.J. Such-Devesa, 2018. Is hotel efficiency necessary for tourism destination competitiveness? An integrated approach. Tourism Econ., 24: 3-26.

Mishenin, Y., I. Koblianska, V. Medvid and Y. Maistrenko, 2018. Sustainable regional development policy formation: Role of industrial ecology and logistics. Entrepreneurship Sustainability Issues, 6: 329-341.

Mowforth, M. and I. Munt, 2015. Tourism and Sustainability: Development, Globalization and New Tourism in the Third World. 4th Edn., Routledge, Abingdon, UK., ISBN: 978-1-138-01325-4, Pages: 456.

Murphy, L., P. Benckendorff and G. Moscardo, 2007. Linking travel motivation, tourist self-image and destination brand personality. J. Travel Tourism Marketing, 22: 45-59.

Nunkoo, R. and H. Ramkissoon, 2011. Developing a community support model for tourism. Ann. Tourism Res., 38: 964-988.

Peng, D.X. and F. Lai, 2012. Using partial least squares in operations management research: A practical guideline and summary of past research. J. Oper. Manage., 30: 467-480.

Pesonen, J. and R. Komppula, 2010. Rural wellbeing tourism: Motivations and expectations. J. Hospitality Tourism Manage., 17: 150-157. 
Pulido-Fernandez, J.I., L. Andrades-Caldito and M. Sanchez-Rivero, 2015. Is sustainable tourism an obstacle to the economic performance of the tourism industry? Evidence from an international empirical study. J. Sustainable Tourism, 23: 47-64.

Rajiani, I. and S. Kot, 2018. The prospective consumers of the Indonesian green aviation initiative for sustainable development in air transportation. Sustainability, Vol. 10,

Reitsamer, B.F., A. Brunner-Sperdin and N.E. Stokburger-Sauer, 2016. Destination attractiveness and destination attachment: The mediating role of tourists attitude. Tourism Manage. Perspect., 19: 93-101.

Ringle, C.M., S. Wende and J.M. Becker, 2015. SmartPLS 3. SmartPLS GmbH, Bonningstedt, Germany.
Sanches-Pereira, A., B. Onguglo, H. Pacini, M.F. Gomez, S.T. Coelho and M.K. Muwanga, 2017. Fostering local sustainable development in Tanzania by enhancing linkages between tourism and small-scale agriculture. J. Cleaner Prod., 162: 1567-1581.

Tenenhaus, M., V.E. Vinzi, Y.M. Chatelin and C. Lauro, 2005. PLS path modeling. Comput. Stat. Data Anal., 48: 159-205.

Walliman, N., 2011. Research Methods: The Basics. Routledge Publishing, Madison Avenue, New York, ISBN:9780415489911, Pages: 190.

Wang, C.C., C. Cater and T. Low, 2016. Political challenges in community-based ecotourism. J. Sustainable Tourism, 24: 1555-1568.

Wetzels, M., G.O. Schroder and C.V. Oppen, 2009. Using PLS path modeling for assessing hierarchical construct models: Guidelines and empirical illustration. MIS. Q., 33: 177-195. 